\title{
O texto, a palavra e o silêncio A Ode marítima de Claude Régy
}

\author{
Hélder Wasterlain
}

\author{
Arre! Por não poder agir d'acordo \\ com o meu delírio! \\ Arre! Por andar sempre agarrado \\ às saias da civilização!
}

Álvaro de Campos

Iorque. Um japonês fotografa a ponte, metade feita, metade desfeita, ícone ou metáfora da "velha Europa" ou nada disso. 0 público aumenta e a oferta teatral tenta ser à proporção. De repente, fachadas, gradeamentos, postes, cafés e lojas, que compõem esta cidade, vestem-se de cartazes promocionais. 0 teatro, esse, faz-se em cada esquina porque nunca se sabe onde andam os senhores com dinheiro ou os caça talentos. Nesse ano, nesta confusão, Claude Régy apresenta na grande sala de espectáculos do Festival, Cour d'honneur du Palais des Papes, com cerca de 2.000 lugares, Le Nom d'CEdipe d'après Le Chant du corps interdit, um texto de Hélène Cixous. 0 espectáculo, um teatro musical, é denso e desagrada a um certo público habituado a correntes teatrais mais espontâneas em que a imagem é mais importante do que o texto e a sua palavra. Para Claude Régy é o início da dissidência com o rumo estético que o Festival assumia ter. Após esta experiência, Régy compreendeu que o seu trabalho não se enquadrava de todo naquele cenário pesadamente histórico que têm os muros do Palais des Papes, nem naquele desenfreado consumo teatral. $\mathrm{Na}$ verdade, as suas encenações não eram feitas para grandes públicos, o seu trabalho requeria mais intimidade e concentração, programas estéticos que não se coadunavam com o vento, o barulho e a impaciência dos espectadores. Claude Régy aprendeu e nunca mais marcou presença no Festival d'Avignon.

Trinta anos depois, a organização do Festival, em conferência de imprensa, anuncia as pazes, a encomenda e o regresso. Claude Régy, já com 86 anos de idade, aceita, mas em troca pede uma sala, silêncio, tempo e paciência. 0 texto? Aquele que ele acha ser suficientemente universal, absoluto e ideal: Ode Maritima, de Fernando Pessoa. Para quem conhece o trabalho de Claude - e o público português recordar-se-á do perturbador espectáculo 4.48 Psychose, da Sarah Kane, apresentado na Culturgest em 2003 entende que este é um texto feito à medida das exigências teatrais do encenador. A Ode Marítima é um poema com um ritmo regular em que as palavras funcionam como um delicado mecanismo de relógio suiço, sempre certo, cujo tempo não é o da nossa realidade, mas o da poesia. Este é um texto, que tal como um fato, veste bem as medidas do encenador: texto, palavra e silêncio. 
Ode maritima de Álvaro de Campos,

enc. Claude Régy,

Festival de Avignon, 2009 ( Jean-Quentin Châtelain)

fot. Mário Del Curto.
No que diz respeito ao processo de trabalho deste projecto, Claude Régy trabalhou inicialmente com um tradutor (Parcídio Gonçalves) e um dramaturgista (Sébastien Derrey). Não falando outra língua que para além do francês, Régy procurou reconhecer a sonoridade das palavras, a sua origem, o seu significado e a sua vida. 0 desejo é chegar à parte invisível da linguagem, essa parte inconsciente que está dentro dela e que muitas vezes os autores não são capazes de a controlar. Depois do trabalho preparatório, 0 texto acaba por ter um ritmo e uma sonoridade própria. Não é por acaso que, quando questionado sobre a opção de traduzir a palavra "saudade" por "melancolie" e "tristesse", Claude Régy responda sem hesitações que é uma questão de ritmo e de escuta, até porque a palavra "saudade" não tem qualquer valor simbólico ou sentimental para um francês. No entanto, um francês já entende o significado das palavras "melancolie" ou "tristesse" 1

Na prática, esta forma de amestrar a linguagem do autor, para que ela seja pronunciada pelo actor $e$ compreendida pelo espectador, funciona. É um trabalho exigente, tanto para o actor como para o espectador. A cadência envolve-nos num ambiente etéreo, asséptico e laboratorial, em que todos os elementos, desde a luz ate à cenografia, figurino e som, foram concebidos para que a atenção do público não se desvie do centro, que é onde está o actor, a palavra, o texto e o autor.

Quanto ao trabalho de actor, Claude Régy relembra várias vezes, ao longo dos ensaios, a frase de Marguerite Duras: "0 jogo dos actores não ajuda a escrita. Mata a escrita". Sob este princípio, o actor não deve querer representar o texto, mas deve deixar o texto representarse. 0 actor é visto como um veículo de expressão do texto e para isso ele tem de saber deixar-se levar por ele. Conhecendo esta praxis compreendemos melhor o trabalho realizado pelo actor Jean-Quentin Châtelain. São duas horas em pé, sem se mexer, numa tensão corporal que chega a causar incómodo para quem vê, movendo apenas o rosto, olhar fixo, levando por uma vez só as mãos à boca. Tudo está focalizado na palavra e no texto. Tudo está concebido para que o espectador não desvie a sua atenção. E depois há o silêncio entre as palavras, aquele silêncio que não sabemos se é do actor à procura do texto perdido ou se é o tempo que leva uma palavra a chegar à boca.

Esta encenação coloca-nos numa fronteira dificil de enquadrar espacial e temporalmente. Claude Régy, e na sequência da ideia de laboratório, quer testar a nossa capacidade de ouvir e de atenção. Será que ainda somos capazes de ouvir? Ouvir poesia em teatro?

0 cenário - da autoria de Sallahdyin Khatir - é neutro e minimalista, mas, ao mesmo tempo, predicado para múltiplas interpretações e conjecturas: a quilha de um barco comercial, uma onda gigante? E aquela ponte inacabada: um pontão, abismo, ou início de um precipicio? Em resposta a estas leituras Claude Régy é peremptório: o público pode ter as interpretações que quiser, não esperem uma resposta reveladora "é isto!", porque tudo está
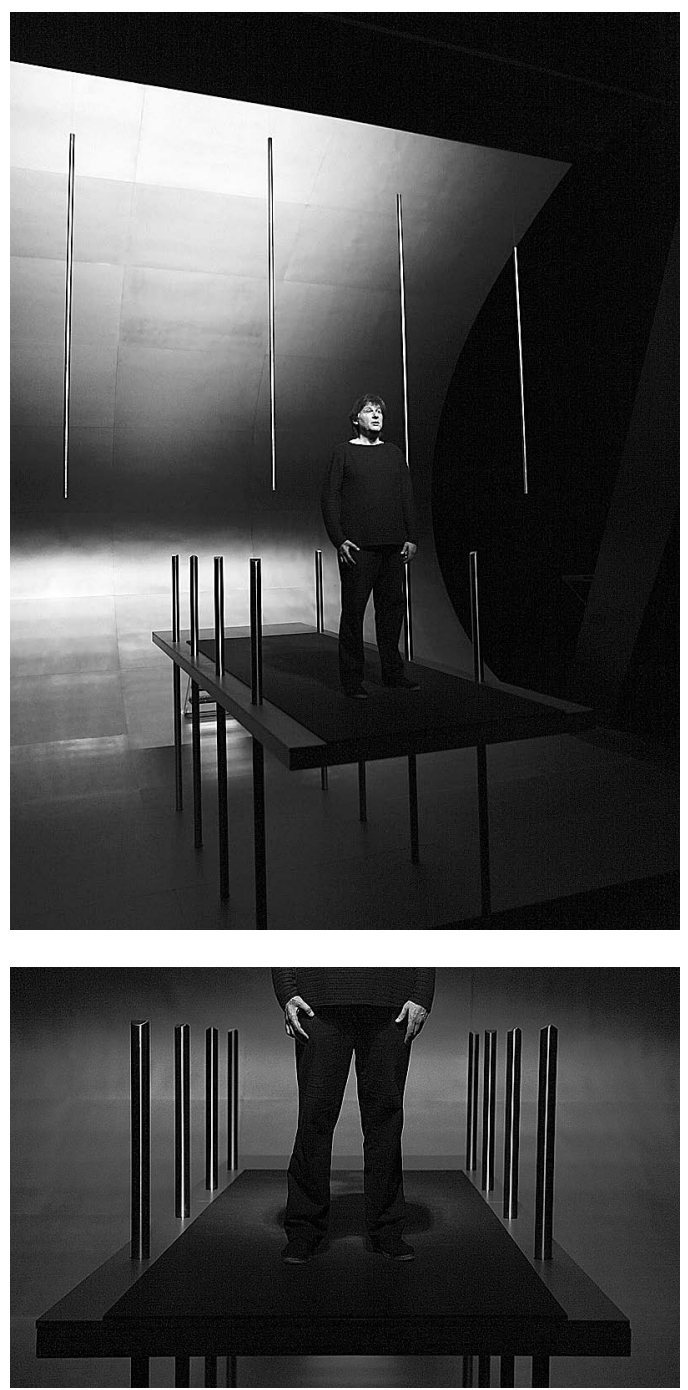

concebido para servir o que realmente interessa: o actor e aquilo que ele tem para dizer.

Aos 86 anos de idade, Claude Régy prefere a noção de força e intensidade, à noção do "belo" aristotélico. Ode maritima é uma encenação que traz à memória um tempo teatral antigo. Confrontado com o facto de algumas pessoas, sobretudo jovens, terem saído a meio do espectáculo, 0 encenador responde muito calmamente que está habituado à falta de paciência e que muitas vezes as pessoas entram enganadas porque não conhecem o seu trabalho, porque vão à procura de coisas que não existem.

Provavelmente, o público português terá a oportunidade de ver a Ode Maritima inserida na programação do próximo Festival de Teatro de Almada, em 2010. Nessa altura iremos ouvir Álvaro de Campos sem legendas e com a palavra saudade traduzida. Passei dois meses a tentar escrever sobre este espectáculo. Levei o meu tempo. Foi propositado.

\section{Referências bibliográficas}

PESSOA, Fernando (2009), Ode marítima, Tradução Dominique Touati revista por Parcídio Gonçalves e Claude Régy, versão bilingue, Paris, Éditions de la Différence.

ARVERS, Fabienne e SOURD, Patrick (2009), "Entretien avec Claude Régy". Édition Festival d'Avignon in Les Inrockuptibles, pp.33-36. 